\title{
Hydroperiod and phenology prediction in a Central Kalimantan peat swamp forest by using MODIS data
}

\author{
Sawahiko Shimada ${ }^{1}$, Hidenori TAKAHASHI ${ }^{2}$ and Suwido H. Limin ${ }^{3}$ \\ Department of Bioproduction and Environment Engineering, Tokyo University of Agriculture. Sakuragaoka 1-1-1, Setagaya-ku, Tokyo 156 \\ -8502, Japan. Phone: +81-3-5477-2767, Fax: +81-3-5477-2620, E-mail: shima123@nodai.ac.jp \\ ${ }^{2}$ Graduate School of Environmental Earth Science, Hokkaido University, N. 10, W. 5, Kita-ku, Sapporo 060-0810, Japan. Phone: +81-11-706- \\ 2221, Fax: +81-11-706-2221, E-mail: htaka@ees.hokudai.ac.jp \\ Faculty of Agriculture, University of Palangka Raya. Jl. Yos Sudarso, Central Kalimantan, Indonesia. Phone: +62-536-25728, Fax: +62-536- \\ 25728, E-mail: suwido@palangkaraya.wasantara.net.id
}

\begin{abstract}
In this study, in order to monitor seasonality function in peat swamp forests by remotely sensed data; we attempted to predict the hydroperiod and phenology of a peat swamp forest in Central Kalimantan using multi-temporal TERRA-MODIS data. We developed a niche method to compress the monthly NDVI images of a oneyear period into four seasonal NDVI images. The four seasonal periods were discriminated by using the degree and aspect of the local groundwater levels. Five phenology types, i.e., Dry-philous, Dry-phobous, Wet-philous, Wet-phobous, and Mixed phenology, were classified from the seasonal fluctuation in NDVI values. Water-deficit stress of vegetation during the dry season in the Dryphobous forest phenology type, and the waterflooding stress of vegetation during the wet season in the Wet-phobous forest phenology type were indicated. The strong effect of the hydroperiod on the forest phenology of peat swamp forests is clarified.
\end{abstract}

Key words: Central Kalimantan, hydroperiod, peat swamp forest, phenology, TERRA-MODIS

Tropical peat swamp forests (PSFs) have important roles in many global processes, such as carbon sequestration, hydrological regulation, and biodiversity maintenance. A lot of studies have been done to evaluate the importance of PSFs in such functions at the local level scale. However, the process of extending the scale and link with the wide areal information, such as GIS data and remotely sensed data, is still being developed. In this study, in order to monitor the functional seasonality of PSFs by remotely sensed data, we attempted to predict the hydroperiod and phenology of a PSF in Central Kalimantan using TERRA-
MODIS multi-temporal vegetation index data.

The Normalized Difference Vegetation Index (NDVI), has been reported to have correlations with many physical and physiological characteristics of vegetation, e.g., vegetation cover ratio, leaf area index (LAI), biomass, chlorophyll amount, absorbed photosynthetic photon flux density (PPFD), transpiration, and photosynthetic rate (Nishida et al., 2000). The NDVI is calculated by the following equation:

$$
\mathrm{NDVI}=\frac{\text { NIR-RED }}{\text { NIR+RED }} \quad \text { eq(1), }
$$

where NIR and RED are radiative reflectance values at the wavelength of near-infrared and visible red, respectively. In this study, we used this NDVI value as an index of vegetation activity, and traced the seasonal fluctuation over a one-year period (Feb. 2001 - Jan. 2002) in order to determine phenology types.

\section{MATERIALS AND METHODS}

Deriving smoothed monthly NDVI images

The multi-temporal 16-day composite vegetation index MODIS datasets (L3 GLOBAL 500M ISIN GRID V003) over the Central Kalimantan area were acquired via the Earth Observing System (EOS) Gateway (http:// edcimswww.cr.uss.gov/pub/imswelcome/). The composite monthly NDVI images (Jan. 2001 - Feb. 2002) were created by combining these 16-day composite NDVI images. The 12 monthly NDVI images (Feb. 2001 - Jan. 2002) were eventually completed after smoothing by a 3-month moving median time series filter in order to eliminate cloud and noise. During the entire process Imagine 8.5 software was used to deal with the MODIS images. 


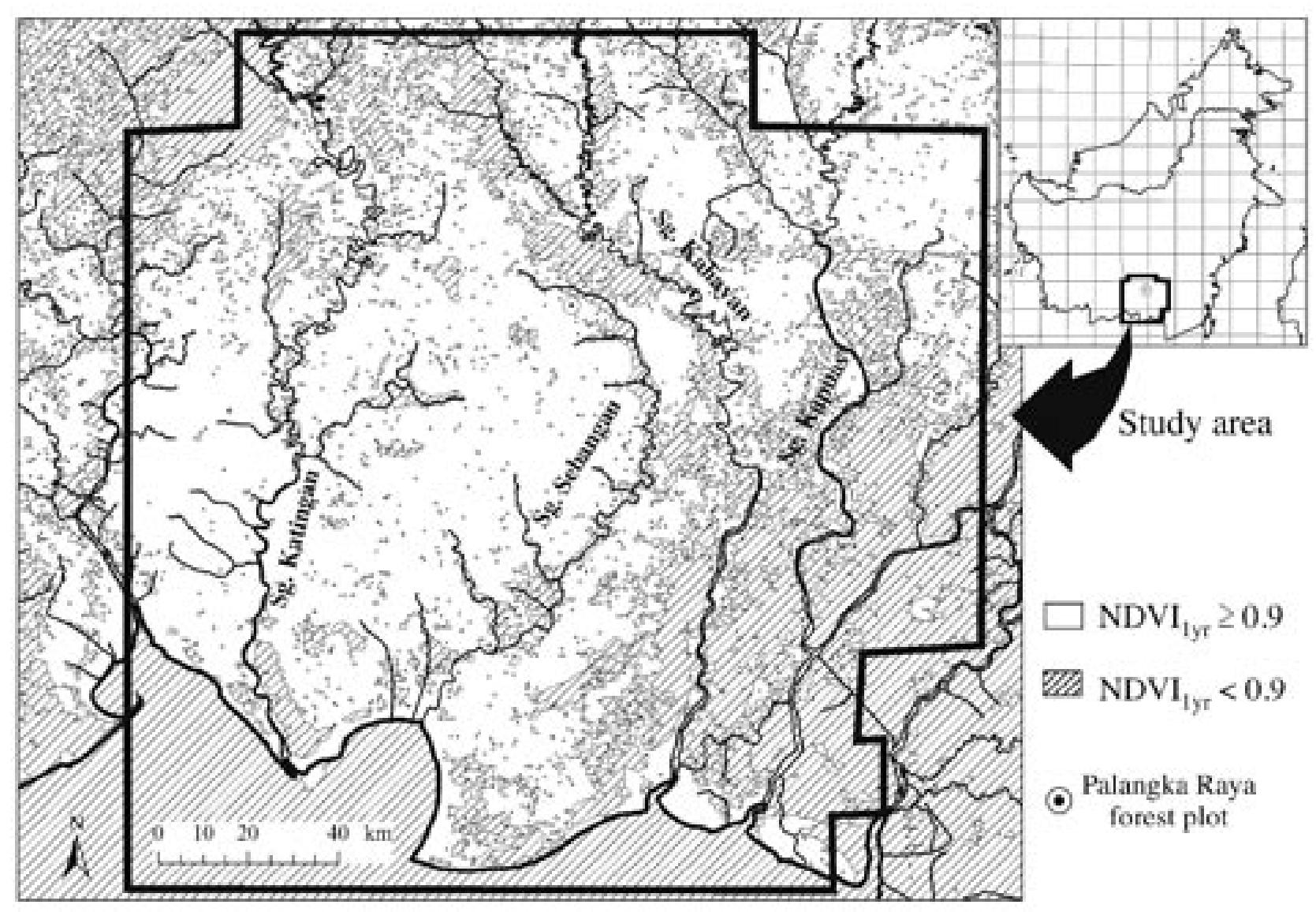

Fig. 1. Classified land cover map of peat swamp forest $\left(\mathrm{NDVI}_{1 \mathrm{yr}} \geq 0.9\right)$ and non forested area $\left(\mathrm{NDVI}_{1 \mathrm{yr}}<0.9\right)$ in Central Kalimantan superimposed by the areal extent of the study area for analysis.

Topographic indices and extent of the study area Considering the areal extent of PSF based on Land system map and Land Use Map of RePPProT (1985) (Shimada et al., 2001), the one-year mean NDVI value $\left(\mathrm{NDVI}_{1 \mathrm{y}}\right)$ of 0.9 was determined as the threshold value to divide forested (PSF; $\mathrm{NDVI}_{\mathrm{yr}} \geq 0.9$ ) and non forested areas $\left(\mathrm{NDVI}_{1 \mathrm{yr}}<0.9\right)$ (Fig. 1-B). The phenological classification was conducted on both the forested and non forested areas, then the difference in the characteristics between the two land cover types was compared.

In order to examine the effect of the topographic location on vegetation phenology, a digital elevation model (DEM) of 500-m x 500-m and digitized line data of river drainage in Central Kalimantan were derived from BAKOSURTANAL (1997) (cf. Shimada et al., 2000). Three topographic indices, i.e. slope, convexity (CVI; Fig. 2-A), and cost weighted distance to the nearest natural drainage system $\left(\mathrm{CWD}_{\mathrm{dr}} ;\right.$ Fig. $\left.2-\mathrm{B}\right)$, were calculated using ESRI's ArcGIS 8.1 software. The CVI was defined as the following equation:

$$
\mathrm{CVI}=\mathrm{h}_{\text {Mean }}-\frac{\mathrm{h}_{\text {Max }}+\mathrm{h}_{\text {Min }}}{2}
$$

where $\mathrm{h}_{\text {Mean }}, \mathrm{h}_{\text {Max }}$, and $\mathrm{h}_{\text {Min }}$ are the maximum, minimum, and mean elevation values, respectively, within a $2-\mathrm{km}$ radius circle of the focal point. The absolute value of CVI represents the degree of convexity $(\mathrm{CVI}>0)$ and concavity $(\mathrm{CVI}<0)$. The $\mathrm{CWD}_{\mathrm{dr}}$ was calculated by setting the elevation as the cost value. The least accumulated cost (i.e., elevation) to get to the nearest river or sea was determined first, and then the cost weighted distance was calculated. This value is the combined index of elevation and distance from the drainage system. Since the areal extent of the DEM is limited, the study area was modified to within where DEM data existed (Fig. 1).

\section{Discrimination of seasonal period}

Typically, the PSFs of the Central Kalimantan region have a dry season (evapotranspiration exceeds precipitation) of ca. 2-3 consecutive months in a year (Neuzil, 1997). The vegetation of the PSF might be affected by this seasonality, especially the fluctuation of groundwater 


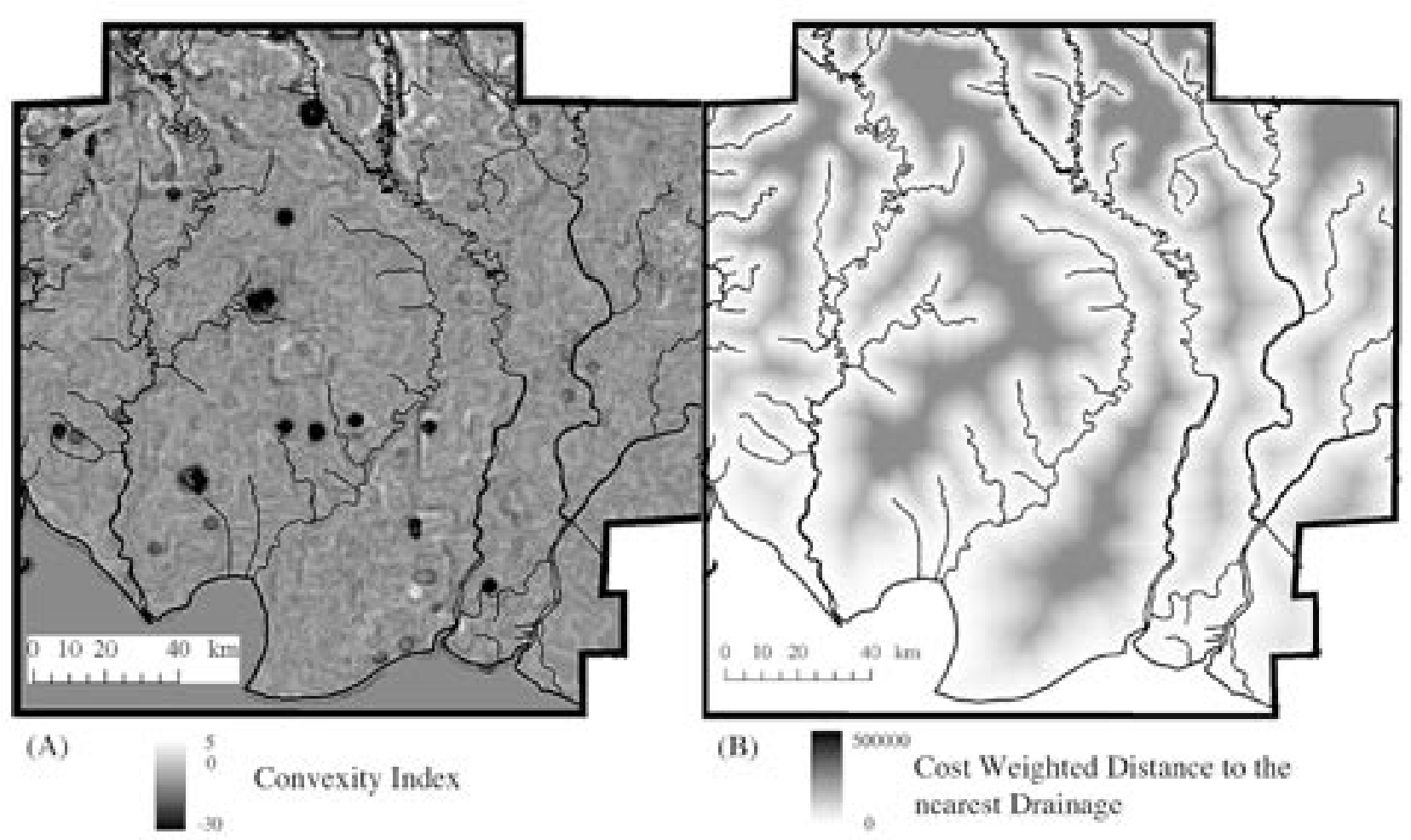

Fig. 2. Map of (A) convexity index (CVI) and (B) cost (elevation value) weighted distance to the nearest natural drainage system $\left(\mathrm{CWD}_{\mathrm{dr}}\right)$ within the study area of Central Kalimantan.

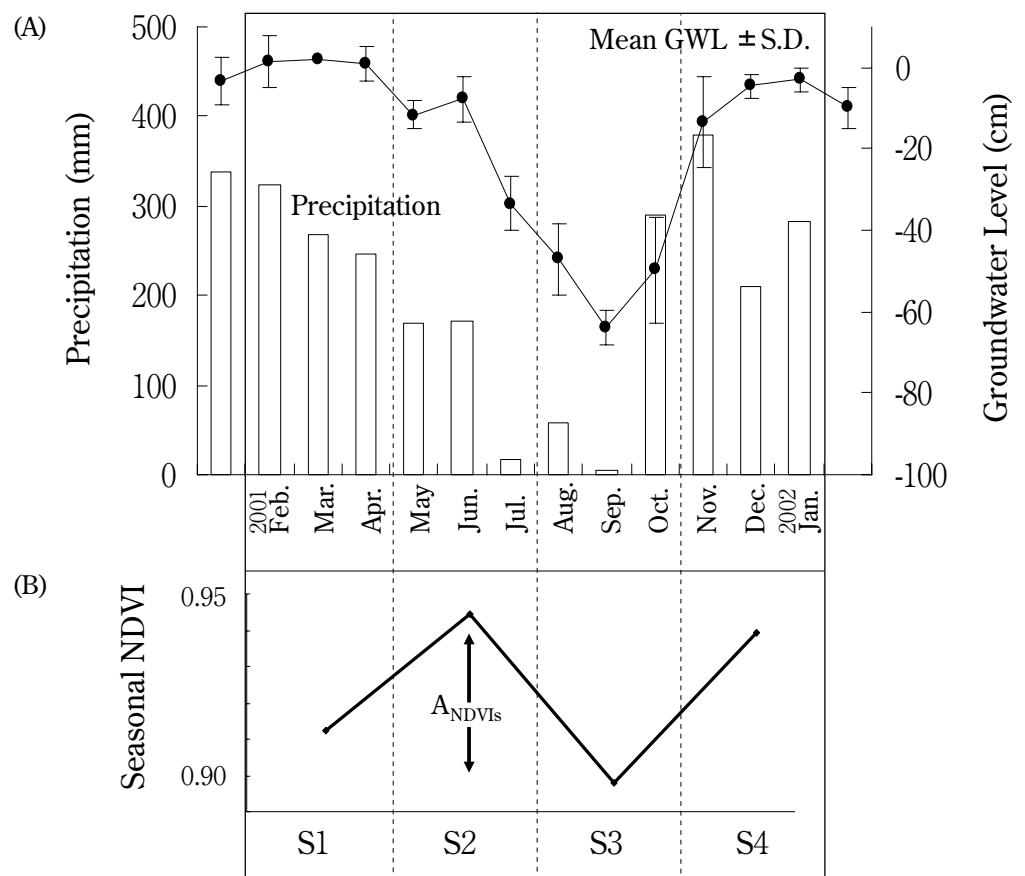

Fig. 3. (A) Monthly precipitation and monthly mean groundwater level ( \pm S.D.) and (B) seasonal NDVI fluctuation at Palangkara Raya forest plot (cf. Fig. 1). $\mathrm{NDVI}_{\mathrm{S}-\mathrm{Max}}=\mathrm{NDVI}_{\mathrm{S} 2}, \mathrm{NDVI}_{\mathrm{S}-\mathrm{Min}}=\mathrm{NDVI}_{\mathrm{S} 3}$ is clear and this plot can be classified to be "Dry-phobous" (cf. Fig. 4). Seasonal NDVI amplitude $\left(A_{\mathrm{NDVI}}\right)$ can be calculated by $\mathrm{NDVI}_{\mathrm{s} 2}-\mathrm{NDVI}_{\mathrm{s} 3}$. 
levels. The monthly precipitation and groundwater level data, for the same period as the multi-temporal MODIS data (Feb. 2001 -Jan. 2002), were obtained in the field of the Palangka Raya forest plot (Plot-1B; Fig. 1, Fig. 3-A). Since the evapotranspiration of this plot is reported to be ca. $3.5 \mathrm{~mm} \mathrm{day}^{-1}$ (Kayama, 2000), the 3month period of June-August can be defined as the dry season of 2002 in terms of rainfall deficit. However, the groundwater levels seem to fluctuate a few months after the alteration of the precipitation rate (Fig. 3-A). In order to trace the vegetation sensitivity to the fluctuation of the groundwater level, the seasonal periods in this study were divided based on the degree or aspect of the groundwater level. For this reason, a one-year period was divided into 4 seasonal periods (i.e. S1, S2, S3, and S4) consisting of 3 consecutive months, respectively, as shown in Fig. 3-B. The seasonal periods of S1 and S4 are the seasons of high groundwater level, $\mathrm{S} 2$ is the transitional season when the groundwater level is decreasing, and S3 is the season of low groundwater level.

\section{Phenological classification}

We calculated the mean NDVI values of the 4 seasonal periods $\left(\mathrm{NDVI}_{\mathrm{s} 1}, \mathrm{NDVI}_{\mathrm{s} 2}, \mathrm{NDVI}_{\mathrm{s} 3}\right.$, and $\left.\mathrm{NDVI}_{\mathrm{s} 4}\right)$, for all the $500 \mathrm{~m} \times 500 \mathrm{~m}$ pixels, from the 12 monthly NDVI images. For each pixel, the seasonal NDVI fluctuation can be seen (cf. Fig. 3-B). We then calculated the following 3 phenological indicators for all the pixels; i.e., the maximum and minimum seasonal NDVI values $\left(\mathrm{NDVI}_{\mathrm{S}-}\right.$ Max and $\mathrm{NDVI}_{\mathrm{S}-\mathrm{Min}}$, respectively) within the 4 periods, and the amplitude of seasonal NDVI $\left(\mathrm{A}_{\mathrm{NDVIs}}: \mathrm{NDVI}_{\mathrm{S}-\mathrm{Max}}-\mathrm{NDVI}_{\mathrm{S}}\right.$ -Min) (cf. Fig. 3-B).

Focusing on the only dry season of S3 (cf. Fig. 3-B), we selected pixels that contained $\mathrm{NDVI}_{\mathrm{S}-\mathrm{Max}}$ and $\mathrm{NDVI}_{\mathrm{S}}$ -Min during the S3 period, and classified such pixels as "Dry-philous" and "Dry-phobous" phenology types, respectively. The pixels that weren't classified as either were then divided into 2 further types, focusing on the $\mathrm{NDVI}_{\mathrm{S}-\mathrm{Max}}$ and $\mathrm{NDVI}_{\mathrm{S}-\mathrm{Min}}$ occurring in the wet season (S1 or S4). These were classified as "Wet-philous" and "Wet -phobous" phenology types, respectively. However,

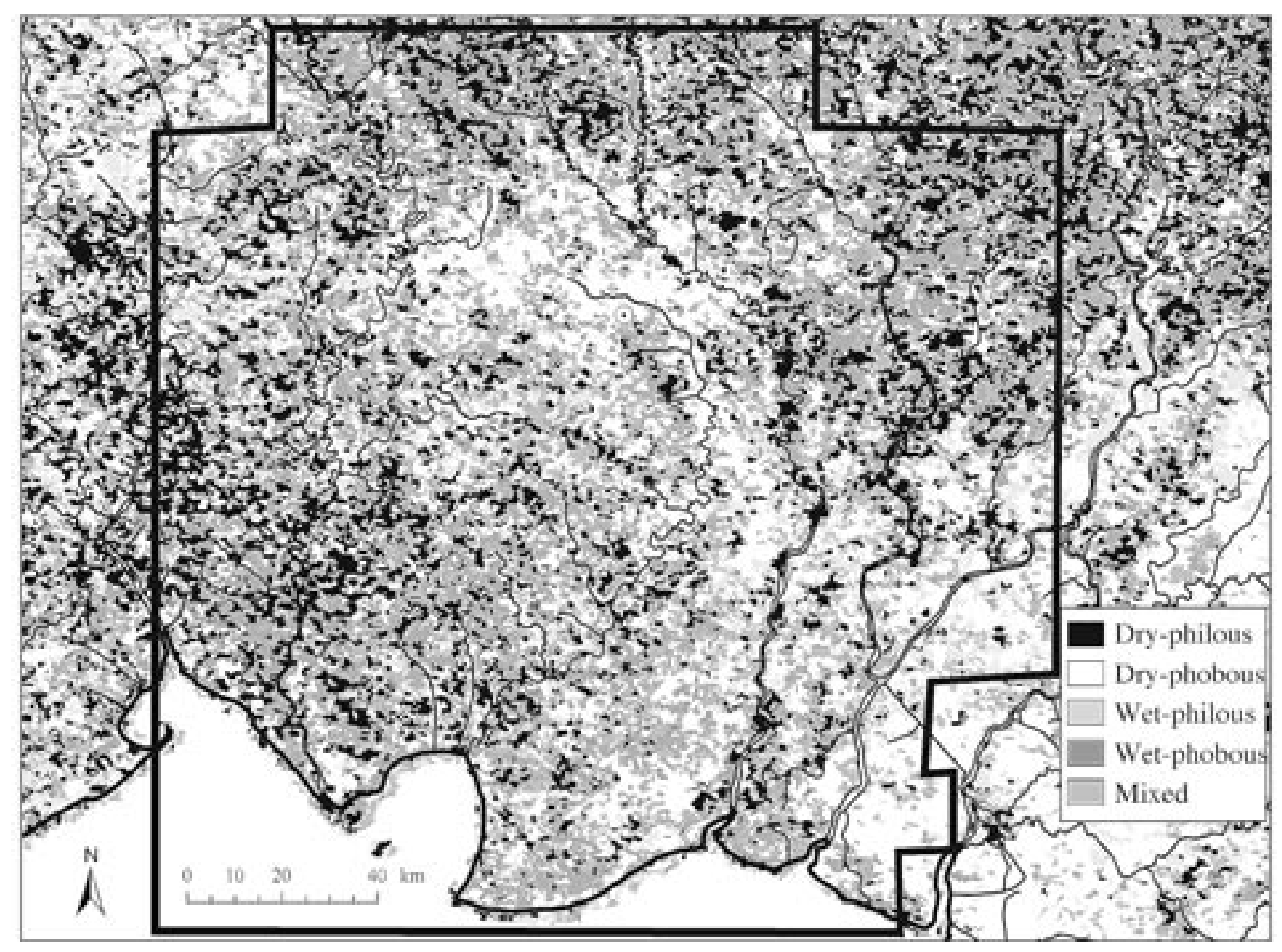

Fig. 4. Classified map of phenology type in Central Kalimantan superimposed by the areal extent of the study area for analysis. 
pixels that couldn't be classified into any of the above 4 phenology types still existed. We classified these pixels as a "Mixed" phenology type. Finally, the focal majority filter smoothed the derived phenology map in order to eliminate any small patches $<4$ pixels (i.e., $<1 \mathrm{~km}^{2}$ ) (Fig. 4). The relationships of these topographic indices and phenology types were then analyzed.

\section{RESULTS AND DISCUSSION}

Fig. 5 shows the areal distribution of the phenology types

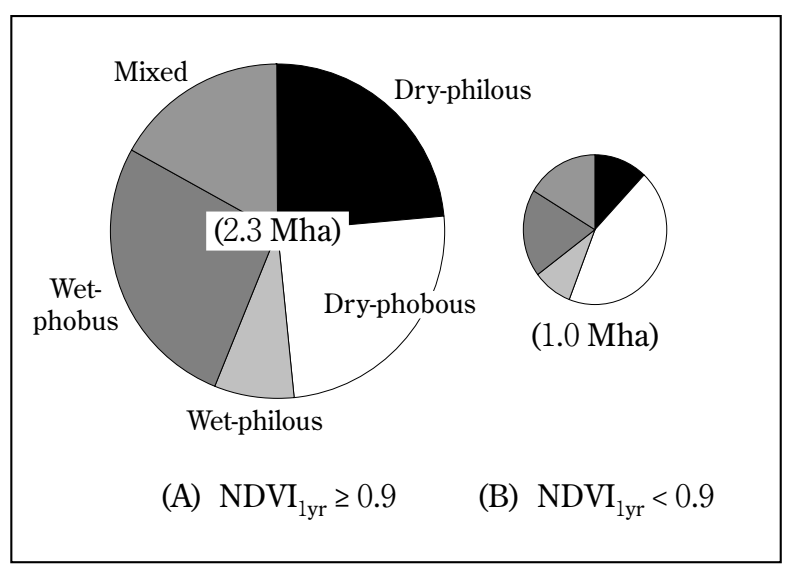

Fig. 5. Areal distribution of the phenology types in both (A) forested area $\left(\mathrm{NDVI}_{1 \mathrm{yr}} \geq 0.9\right)$ and (B) non forested area $\left(\mathrm{NDVI}_{1 \mathrm{yr}}<0.9\right)$. The size difference of the two pie charts reflects the areal ratio of both land cover types. in both land cover types. Most of the PSF study area (i.e., $\mathrm{NDVI}_{1 \mathrm{yr}} \geq 0.9$ ) seems to be dominated by vegetation types that are not active in the wet season (i.e., Dry-philous and Wet-phobous phenology types), in other words, the ombrophobous type. The Dry-phobous type occupies almost half $(43.7 \%)$ of the non-forested regions $\left(\mathrm{NDVI}_{1 \mathrm{yr}}\right.$ $<0.9$ ) of the study area. It should be noted that the large cultivated land area around the lower catchment of the River (Sg.) Kapuas (cf. Fig. 1) contributed largely to the characteristics of the non-forested areas.

The non-forested areas are anticipated to consist of cultivated lands, floodplain areas, residual hills, urban areas, and burnt forests. The significantly greater $\left(P<0.01\right.$, Scheffé's test) value of the $\mathrm{A}_{\mathrm{NDVIs}}$ at non-forested areas (Fig. 6-A) can be explained by the planting and harvesting on cultivated lands. The significantly $(P<0.01)$ lower value of $\mathrm{CWD}_{\mathrm{dr}}$ in non-forested areas (Fig. 6D) indicates that PSFs exist or remain farther inside watersheds, where deeper peat layers exist. The residual hills can be detected by the extremely low convex index value (Fig. 2-A). The residual hill, the place with a high degree of concavity (inverse value of CVI) and slope, tends to be classified as Wet-phobous within the nonforested land cover type (Fig. 6-B, -C).

The mean $A_{\mathrm{NDVIs}}$ values of the PSF phenology types are significantly different $(P<0.05)$ between Wet-phobous and Mixed types, which $\mathrm{A}_{\mathrm{NDVIs}}$ values are significantly $(P<0.01)$ greater than the other types (Fig. 6-A). According to the significantly $(P<0.01)$ lower value of
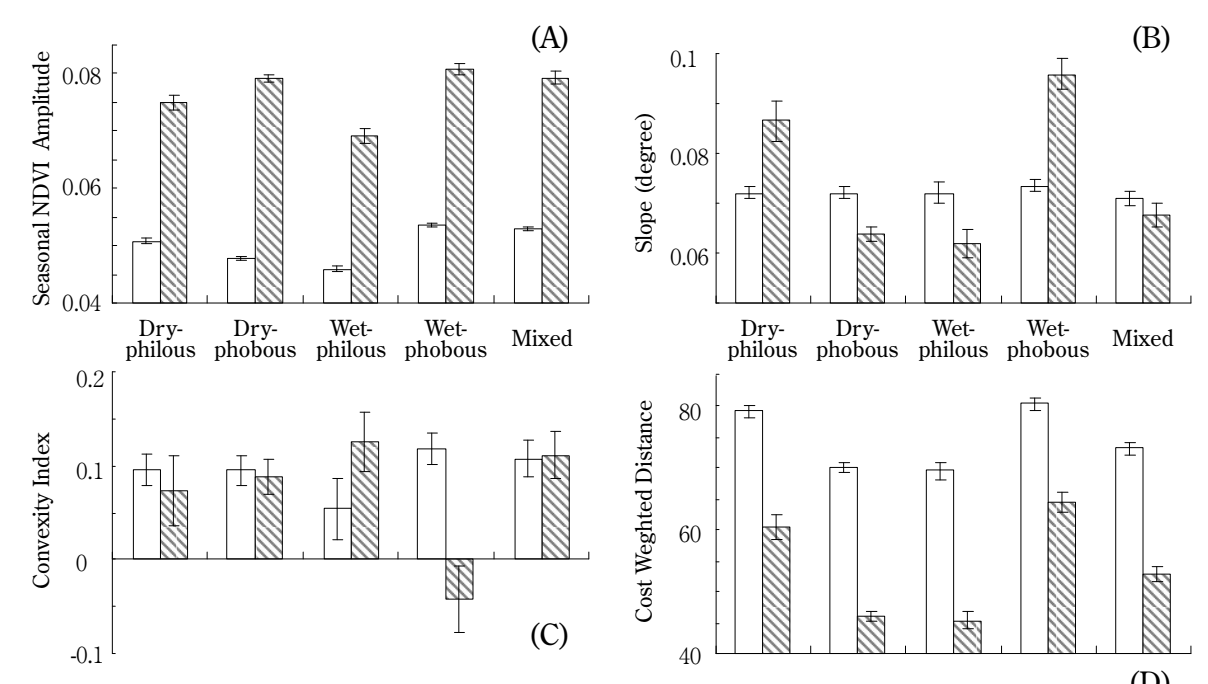

(B)

$$
\mathrm{NDVI}_{1 \mathrm{yr}} \geq 0.9 \quad \mathbb{N} \mathrm{NDVI}_{1 \mathrm{yr}}<0.9
$$

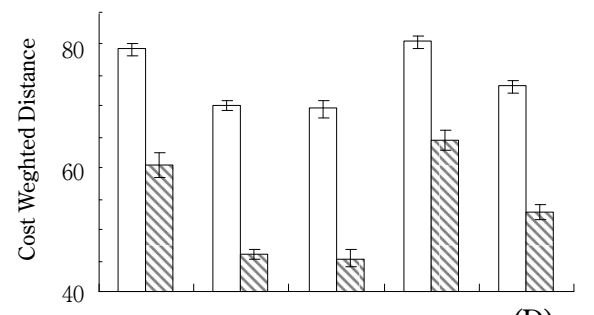

(D)

Fig. 6. Mean ( $\pm 95 \%$ confidence interval) values of $(A)$ seasonal NDVI amplitude $\left(A_{N D V I}\right),(B)$ topographic slope, (C) convex index (CVI), and (D) cost (elevation value) weighted distance to the nearest drainage system $\left(\mathrm{CWD}_{\mathrm{dr}}\right)$ among the phenology types and land use types. 
mean $\mathrm{A}_{\mathrm{NDVIs}}$ in the Wet-philous PSF phenology type, the vegetation activity was relatively constant during the oneyear period. No significant difference $(P>0.05)$ was found in any mean slope values between PSF phenology types (Fig. 6-B). A significant difference $(P<0.01)$ in mean CVI value can only be found between the Wet-philous and Wet-phobous PSF phenology types (Fig. 6-C). The mean $\mathrm{CWD}_{\mathrm{dr}}$ values of Dry-phobous and Wet-philous PSF phenology types are not significantly different $(P>0.05)$, nor is there any difference between the Dryphilous and Wet-phobous PSF phenology types (Fig. 6 $-\mathrm{D})$. The mean $\mathrm{CWD}_{\mathrm{dr}}$ values between the two (pooled) similar phenology types, i.e., Dry-philous + Wet-phobous (ombrophobous type), and Dry-phobous + Wet-philous type (ombrophilous type), are significantly different $(P<0.01)$. These results indicate that the ombrophobous PSF types tend to occur relatively closer to the watershed boundaries than the ombrophilous types.

According to the fluctuation of seasonal NDVI at Plot-1B in relation to the groundwater level (Fig. 3), the depression in vegetation activity in the S3 period seems to be a result of water-deficit stress caused by low groundwater levels. A big patch of Dry-phobous PSF phenology type lies spatially around the upper catchment of Sg. Sebangau (Fig. 1, 4) including Plot-1B. These Dry-phobous places are anticipated to have a similar hydroperiod to Plot-1B and the vegetation is under water -deficit stress during the dry season. Meanwhile, the Wet -phobous PSF phenology type is anticipated to be located at the place where groundwater levels are relatively high so that the vegetation is constrained under water-flooding stress in the wet season.

The analyses reported here, for predicting hydroperiods and phenologies in PSFs, are still relatively rough. However, the methods used in this study can also be applied to the multi-temporal images of much higher resolution remote sensing sensors, i.e., TERRA -MODIS (250-m resolution) and TERRA-ASTER (15 $-\mathrm{m}$ resolution). Furthermore, much more field data on the vegetation physiology, hydrology, and spectral characteristics of vegetation in PSFs are needed for further study.

\section{REFERENCES}

BAKOSURTANAL. 1997. Peta rupabumi Indonesia 1: 50000, National Coordination Agency for Surveys and Mapping.

Kayama, M. 2000. Hydrologic characteristics of tropical peat swamp forest - a case study in Central
Kalimantan, Indonesia., Ms.c. Thesis, Hokkaido Univ., Japan. (in Japanese with English summary)

Neuzil, S. G. 1997. Onset and rate of peat and carbon accumulation in four domed ombrogenous peat deposits, Indonesia. In: Rieley, J. O. \& Page, S. E. (eds.), Biodiversity and Sustainability of Tropical peatlands, 55-72. Samara Publishing Limited, Cardigan.

Nishida, K., Higuchi, A., Kondoh, A. \& Matsuda, S. 2000. Remote sensing of land surface process based on spectral vegetation index and surface radiation temperature. J. Japan Soc. Hydrol. \& Water Resour. 13: 304-312. (in Japanese)

RePPProT. 1985. Land systems and land suitability series at 1:250 000 scale. Accompanying Maps of Review of Phase 1B Results, Central Kalimantan. Regional Physical Planning Programme for Transmigration. UK Overseas Development Administration and Directorate Bina Program. Jakarta, Ministry of Transmigration.

Shimada, S. Takahashi, H., Kaneko, M. \& Haraguchi, A. 2000. The estimation of carbon resource in a tropical peatland: A case study in Central Kalimantan, Indonesia. In: Proceedings of the International Symposium on: Tropical Peatlands. Bogor, Indonesia 1999, Pp. 9-18.

Shimada, S., Takahashi, H., Haraguchi, A. and Kaneko, M. 2001. The carbon content characteristics of tropical peats in Central Kalimantan, Indonesia: estimating their spatial variability in density. Biogeochemistry 53: 249-267.

Received $7^{\text {th }}$ Mar. 2006 Accepted $19^{\text {th }}$ May 2006 